\title{
Death Anxiety and Religious Belief; An Existential Psychology of Religion
}

Is it true that '...if man did not die, if he lived forever, if there were no such thing as death, there would be no religion' (Feuerbach, 1851, 1967, 33)? Are we so scared of death that we try to pursue symbolic and literal immortality? This intriguing book aims to shed light on Feuerbach's contention - and the more recent assertions of Terror Management Theory empirically, and by means of some ingeniously thought-out methods. Of course, anyone expecting simple and definitive answers to these questions will be disappointed - but probably shouldn't expect a clear-cut resolution to matters which have occupied the minds of thinkers such as Feuerbach, Freud, Becker and Marx, to name a few.

The greatest strengths of the book, in my opinion, are its comprehensiveness, rigour and creativity in experimental design. It is clearly based on a doctoral thesis and leaves no stone unturned in addressing a number of fundamental issues, before introducing the original experiments the authors conducted to shed light on their research questions. The book starts out (as it should) with the perennial questions of how to define religiosity and death anxiety (Chapter 1), before reviewing thanatocentric (death-focused) theories of religion from Tylor (1871) to Becker (1973) to Terror Management Theory (Chapter 2). The important question of how to measure faith and fear is the topic of Chapter 3. Much of these chapters cover familiar ground for psychologists and sociologists of religion.

The book is a bit too thesis-like in places and would have benefited from more editing here and there. For instance, there's a bit too much detail about measurement in Chapter 3 for the general reader, and one gets a little bogged down. There are also calculations and formulae in the text which don't render the findings particularly accessible to the layperson (e.g. the statistics in chapter 4). Anyone interested in this level of detail could presumably read the original thesis.

Obviously, it would do a disservice to the authors to reveal too much about the main conclusions drawn from the studies they reviewed and conducted. Suffice it to say, however, that people are perhaps not as afraid of death as thanatocentric theories of religion posit. In general, people are more afraid of illness, injury, animals and public speaking (94) than they are of death, though of course there are huge variations among individuals. Correlational studies show that religious individuals are less death anxious, 'keeping thanatocentric theories alive' (131), but the real question is whether death anxiety could be manipulated in order to demonstrate causal effects on religious and supernatural belief (and vice versa).

Again, without wishing to reveal too much, the authors are to be congratulated for the complexity they bring to the research questions, specifically for comparing the roles of implicit and explicit beliefs in death anxiety. As they point out, there is more to what people believe than what they tell researchers - or indeed themselves! Jong and Halberstadt's inventive way of tapping implicit beliefs allows them to adduce evidence showing that nonbelievers may implicitly accept the supernatural beliefs that explicitly deny (147-148). In some ways this is redolent of the tendency for many individuals to be angry with a god whose very existence they overtly repudiate. 
I found the final chapter, 'The Future of Immortality, Literal and Symbolic', with its musings about alternative forms of immortality, extremely interesting. I felt more could have been made of the fact that while belief in God is declining, belief in heaven (or some kind of afterlife) is not (179-180). As the authors say, there is clearly a 'gap between atheism and extinctivism' (the belief that personal consciousness is terminated at death). The topics of cryonic preservation, whole brain emulation and forms of social media that allow individuals to post from beyond the grave could have been fruitfully and entertainingly expanded upon.

I felt that the key concept of faith in general and its particular manifestation in scientism could have been explicitly examined somewhere in the book, perhaps in the final chapter. The authors allude to faith in the reference to the Epistle to the Hebrews but the concept of faith, so foundational to research in this domain, required more than a passing reference: 'Literal immortality projects -regardless of whether the immortality is conferred by a sovereign God, an immortal soul, a special fruit, an alchemical concoction, or a cabal of biomedical scientists - all seem to require the conviction of things, unseen, the assurance of things hoped for' (184).

Liz Gulliford

Jubilee Centre for Character and Virtues, University of Birmingham, UK

I.z.gulliford@bham.ac.uk 